\title{
Optimization of timber trusses considering joint flexibility
}

\author{
S. Šilih, M. Premrov \& S. Kravanja \\ University of Maribor, Faculty of Civil Engineering, Slovenia
}

\begin{abstract}
This paper presents the optimization of metal-plate-connected plane timber trusses with special emphasis on joint flexibility. The optimization is performed by the non-linear programming approach. Since various truss design parameters such as type of truss configuration, span/depth ratio, number and type of diagonal and vertical members and type of joint connections simultaneously affect each other, all of these parameters are proposed to be considered simultaneously in a single mathematical model. The optimization model for cost optimization of timber trusses was thus developed. The economic objective function was defined to minimize the structure's self-manufacturing costs, subjected to the design, stress and deflection (in)equality constraints. The finite element equations were as the equality constraints defined for the calculation of the internal forces and the deflections of the structure. The stiffness matrix of the structure was composed by considering the fictiously decreased cross-section areas of all the flexible connected elements. Constraints for the dimensioning of the timber members were determined in accordance with Eurocode 5 in order to satisfy the requirements of both the ultimate and the serviceability limit states. The cross-section dimensions and the number of fasteners were defined as independent optimization variables. A numerical example demonstrates the applicability of the presented approach.
\end{abstract}

\section{Introduction}

Timber construction is an important part of the infrastructure in a number of areas around the world. Wood has proved to be quite a resilient material, showing relatively high ductility and low density. In addition, the flexibility of mechanical fasteners provides a high damping capacity between the connected 
timber elements. Well-built timber structures maintain a good performance particularly under the influence of wind and especially earthquake forces.

In the last decades, the application of timber trusses has frequently been noticed in all aspects of building construction. Timber trusses have become known for their pleasing architectural appearance, lightweight design and easy fabrication. The use of timber trusses to bridge over large open areas with a few or no intermediate supports is still on the increase. These trusses are essentially lighter than the analogous beam solutions. Many magnificent space and plane timber trusses have been constructed all over the world, covering public halls, stadiums, exhibition centres and many other buildings. In this field, metal-plateconnected timber trusses have been found to be favourable structures for roof framings for spans greater than 20 meters.

In order to design a satisfactory and optimal timber truss structure with the given load, span and boundary conditions, some main design parameters need to be considered, on which timber truss behaviour basically depends:

- type of truss configuration,

- $\quad$ span/depth ratio,

- $\quad$ number and type of intermediate members (diagonals and verticals),

- type of joint connections.

When a high number of truss design parameters, designer decisions and factors are involved in the analysis, the designing of timber trusses can become a difficult and expensive process. This has forced designers to find simpler and cheaper alternative design methods, adequate at least for the preliminary design state. Several approximate methods have been developed in the recent past with different accuracies of suitability and simplification according to real truss conditions, see [1]. Approximate designing methods which additionally consider the flexibility of the joints in timber trusses with respect to different diagonal members can for example be found in [2-5].

The idea of the present study was to together simultaneously consider all the mentioned design parameters and factors in a single mathematical truss model, where structural optimization is performed rather than classical analysis.

For more than four decades, trusses have not only been successfully optimized but also very frequently used to present, test and improve various optimization techniques. Numerous research papers on this topic have been published since the early 1960s, e.g. [6]. While many papers discuss the topology, shape and discrete sizing optimization particularly of steel trusses, e.g. [7-10]; also the optimization of composite trusses, [11]; timber trusses have been quite neglected.

The paper presents the sizing optimization of metal-plate-connected timber trusses considering the flexibility of the embedded fasteners. The optimization was performed by the non-linear programming (NLP) approach, where all the mentioned design parameters were simultaneously considered as (in)equality constraints. The optimization model for the cost optimization of the timber trusses was developed. An economic objective function was proposed to minimize the structure's self-manufacturing costs, subjected to the design, stress 
and deflection (in)equality constraints. The finite element equations were as the equality constraints defined for the calculation of the internal forces and the deflections of the structure.

\section{Timber truss design criteria}

The design constraints for the timber trusses were determined in accordance with Eurocode 5 [12] in order to satisfy the requirements of both the ultimate (ULS) and the serviceability limit state (SLS). Considering the ULS, the truss members were checked for the tensional as well as the compressive/buckling resistance. The required number of fasteners was also calculated for each joint. At the SLS the vertical deflections of the truss girders were checked.

Since the bracing members (diagonals and verticals) are flexibly connected, their stiffness decreases. In finite element analysis we consider the joint flexibility in such a way that cross-sectional areas $A_{m}$ of all bracing members are replaced by a fictiously decreased cross-section area $A_{m}{ }^{*}[4]$ :

$$
A_{m}^{*}=\frac{A_{m}}{1+\frac{E_{m, \text { mean }} \cdot A_{m}}{L_{m}} \cdot\left(\frac{1}{K_{s e r} \cdot k_{m, 1}}+\frac{1}{K_{s e r} \cdot k_{m, 2}}\right)}
$$

where $k_{m, 1}$ and $k_{m, 2}$ represent the numbers of fasteners at both ends of the considered $m$-th bracing element and $K_{\text {ser }}$ denotes the fasteners' slip modulus, taken for different types of fasteners from Table 7.1 of Eurocode $5 . E_{m \text {,mean }}$ stands for the mean value of the modulus of elasticity.

\section{Optimization of timber trusses}

As the optimization problem of timber trusses is non-linear, e.g. the objective function and (in)equality constraints are non-linear, the non-linear programming optimization (NLP) approach is used. The general NLP optimization problem can be formulated as follows:

$$
\begin{gathered}
\text { Min } z=f(\mathbf{x}) \\
\text { subjected to: } \\
\boldsymbol{h}(\boldsymbol{x})=\mathbf{0} \\
\boldsymbol{g}(\boldsymbol{x}) \leq \mathbf{0} \\
\boldsymbol{x} \in \boldsymbol{X}=\left\{\begin{array}{l}
\boldsymbol{x} \in \boldsymbol{R}^{n}, \boldsymbol{x}^{L O} \leq \boldsymbol{x} \leq \boldsymbol{x}^{U P}
\end{array}\right\}
\end{gathered}
$$

where $\boldsymbol{x}$ is a vector of continuous variables, defined within the compact set $\boldsymbol{X}$. The variables $\boldsymbol{x}$ are calculated between their lower and upper bounds $\boldsymbol{x}^{L O}$ and $\boldsymbol{x}^{U P}$. Functions $f(\boldsymbol{x}), \boldsymbol{h}(\boldsymbol{x})$ and $\boldsymbol{g}(\boldsymbol{x})$ are non-linear functions involved in the objective function $z$, equality and inequality constraints, respectively. All functions $f(\boldsymbol{x}), \boldsymbol{h}(\boldsymbol{x})$ and $\boldsymbol{g}(\boldsymbol{x})$ must be continuous and differentiable. 
In the context of structural optimization, variables include dimensions, cross-section characteristics, strains, materials characteristics, stresses, economic parameters, etc. Equality and inequality constraints and the bounds of the variables represent a rigorous system of the design, loading, stress, deflections and stability functions taken from the structural analysis. The optimization of the structures may include various objectives worthy of consideration. The most popular criterion used today is the minimization of mass. In this paper, an economic objective function is proposed to minimize the structure's selfmanufacturing costs. Hence, the trade-offs between different materials can be appropriately accounted for.

The optimization model TTO (Timber Truss Optimization) for the optimization of timber trusses was developed according to the above NLP model formulation. GAMS (General Algebraic Modeling System), [13], was used as the interface for mathematical modeling and data inputs/outputs.

A general timber truss layout with its characteristic elements (upper and lower chord, verticals, diagonals) is presented in Figure 1, where $x_{i}$ represents the local longitudinal axis of element $i$, while $y_{i}$ and $z_{i}$ represent the principal axes of the cross-section of the element $i$; the axes $\mathrm{X}$ and $\mathrm{Y}$ form the global coordinate system of the structure. $A_{i}$ and $l_{i}$ stand for the cross-section area and the length of member $i$, respectively. The cross-sections are considered to be rectangular, where $b_{i}$ and $h_{i}$ represent the width and the height of the cross-section of the truss member $i$.

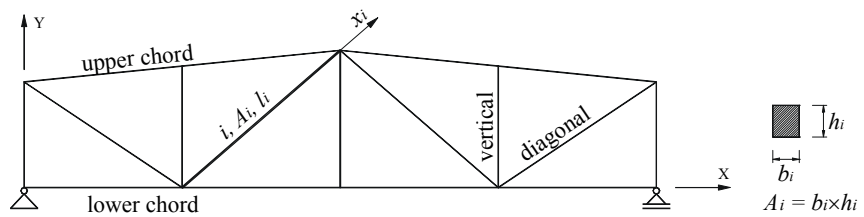

Figure 1: $\quad$ Plain timber truss.

An economic objective function is defined in the model to minimize the structure's self-manufacturing costs, subjected to design, stress and stability constraints, known from structural analysis. Internal forces are proposed to be determined by the finite element equations, while the dimensioning is performed in accordance with Eurocode 5. The objective function is thus defined:

$$
\min \quad \cos t=c_{t} \cdot \sum_{i=1}^{I} b_{i} h_{i} l_{i}+\left(c_{f m}+c_{f l}\right) \cdot 2 \cdot \sum_{m=1}^{M} k_{m}+\left(c_{f m}+c_{f l}\right) \cdot \sum_{j=1}^{J} k_{j}
$$

where cost represents the self-manufacturing (material and labour) costs of the structure; $c_{t}$ denotes the price of the manufactured and embedded timber material per $\mathrm{m}^{3}$; the sum of the products between widths $b_{i}$, heights $h_{i}$ and lengths $l_{i}$ of $i$, $i \in I$, timber members represents the volume of the truss in $\mathrm{m}^{3}$ (see Figure 1 ); $c_{f m}$ is the material cost of one fastener together with the adjoining steel plates, while 
$c_{f l}$ denotes the manual labour costs for handling, assembling, drilling and bolting, defined per one fastener. Considering that the required number of fasteners is equal for both ends of each intermediate member, the total number of fasteners in the $m$-th member is $2 k_{m}$, where $k_{m}=k_{m, 1}=k_{m, 2}$. The last term of the objective function represents the sum of all fasteners required in joints of the chord members. Variable $k_{j}$ stands for the number of fasteners of the $j$-th joint, $j \in J$. It is evaluated considering the resultant force on account of the axial forces of all intermediate elements connected to joint $j$. Since the dimensions of steel plates depend directly on the number of calculated fasteners, the costs of steel plates are included in the values $c_{f m}$ and $c_{f l}$.

The input data of the optimization model is the truss geometry (coordinates of joints), the supporting and loading conditions, the diameter of the considered fasteners, the thickness of the metal plates, as well as the material characteristics of all the used components (timber, fasteners, plates).

The cross-section dimensions $b_{i}$ and $h_{i}$ of $i, i \in I$, truss timber members and the number of fasteners $k_{m}$ and $k_{j}$ are defined as independent optimization variables.

The finite element equations for the calculation of internal forces and deflections of the structure are defined as equality constraints. The stiffness matrix of the structure is composed by considering the fictiously decreased cross-section areas of all the intermediate timber elements (diagonals and verticals) in accordance with Eq. (1). The ULS and SLS design conditions, described in Section 2 are defined as inequality constraints.

\section{Numerical example}

As a numerical example, a timber truss girder of $30 \mathrm{~m}$ span is presented. The layout of the structure is shown in Figure 2. The truss elements are composed from a glued laminated timber GL32h according to the EN 1194 [14] classification. M14 dowels made of steel S 235 are used as fasteners. Steel plates of $8 \mathrm{~mm}$ thickness made of steel S 235 are additionally placed as the central members of a double shear connection.

The truss is subjected to a permanent load of $2 \mathrm{kN} / \mathrm{m}$ and a variable load of $5 \mathrm{kN} / \mathrm{m}$ (snow load). The self-weight of the truss members was automatically determined through the optimization process with respect to the actual calculated cross-sectional dimensions. The uniform loads are, in the calculation, approximated as nodal forces (see Figure 2).

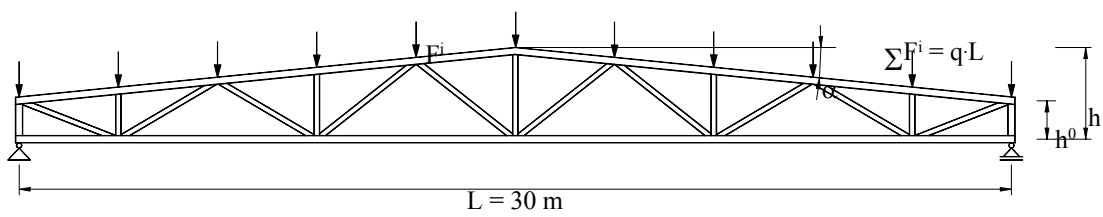

Figure 2: $\quad$ Layout of the timber truss. 
The economic parameters considered for the objective function (2) were $\operatorname{costs} c_{t}=900 \mathrm{EUR} / \mathrm{m}^{3}$ for the GL32h timber, while $c_{f l}=1.5 \mathrm{EUR}$ and $c_{f m}=1.0$ EUR for one M14 S 235 dowel (including the corresponding parts of the steel plates). The lower bound on the cross-section dimensions $b_{i}^{\text {lo }} / h_{i}^{\text {lo }}$ were taken as $12 / 12 \mathrm{~cm}$.

Three different optimization cases of the considered truss were performed, namely $\mathrm{A}, \mathrm{B}$ and $\mathrm{C}$. At truss $\mathrm{A}$ the maximal height $\mathrm{h}$ amounted to $400 \mathrm{~cm}$ $($ span $/$ depth ratio $=7.5)$, while at truss $B$ a lower value of $h=250 \mathrm{~cm}(\mathrm{span} /$ depth ratio $=12$ ) was considered. In both examples $A$ and $B$ the flexibility of joints was taken into account. In addition, the lower truss $(\mathrm{h}=250 \mathrm{~cm})$ was optimized again by ignoring the flexibility of joints (truss $\mathrm{C}$ ). In all cases the inclination of the upper chord $\alpha$ amounted to $7.5 \%$. The vertical displacements of joints at SLS were limited to $\mathrm{L} / 300=10 \mathrm{~cm}$.

Since the NLP optimization handles continuous variables, the obtained variables of the final/optimal solution take some real values between their defined lower and upper bounds. At this stage, the structure is fully exploited considering either the ultimate or the serviceability limit state design conditions. As the aim of this research is to obtain a structure of practical applicability, the final continuous optimal solution was reanalysed with the variables rounded to their nearest upper integer values (i.e. $1 \mathrm{~cm}$ for cross-sectional dimensions and 1 fastener). The NLP optimization was performed by the computer program GAMS/CONOPT2 [15].

Table 1: $\quad$ The obtained optimal results.

\begin{tabular}{|c|c|c|c|}
\hline & Truss A & Truss B & Truss C \\
\hline Total costs & 2984.33 & 3575.14 & 3322.59 \\
\hline Timber mass & 1291.29 & 1486.19 & 1356.99 \\
\hline \multirow{2}{*}{$\begin{array}{r}\text { Chord dimensions } \mathrm{b} / \mathrm{h} \quad[\mathrm{cm}] \\
\text { lower chord } \\
\text { upper chord }\end{array}$} & $16 / 13$ & $17 / 21$ & $17 / 20$ \\
\hline & $18 / 15$ & $21 / 17$ & $21 / 17$ \\
\hline Total number of dowels & 181 & 248 & 244 \\
\hline $\begin{array}{l}\text { Max. deflection without } \\
\text { considering joint flexibility }\end{array}$ & 44.82 & 79.85 & 82.62 \\
\hline $\begin{array}{l}\text { Max. deflection by considering } \\
\text { joint flexibility }\end{array}$ & 59.88 & $95.79^{\mathrm{a}}$ & - \\
\hline
\end{tabular}

$\bar{a}$ It should be noted, that the max. displacements of truss B is not equal to $L / 300=100 \mathrm{~mm}$ due to the rounding of cross sections before the reanalysis. After the first optimization phase (continuous optimization), the SLS conditions were active and the displacement was equal to $100 \mathrm{~mm}$.

The obtained results of the three performed optimizations are presented in Table 1. In order to arrive to appropriate conclusions, it is convenient to present the final results by comparing the optimal costs and the obtained masses between 
different truss alternatives, see Table 2. The influence of the height of the truss on the final results is presented by the ratio $\mathrm{B} / \mathrm{A}$, which represents the ratio between the obtained costs (masses) of the truss $B(h=250 \mathrm{~cm})$ and $A(h=400$ $\mathrm{cm}$ ). The possible error, caused by neglecting the flexibility of the joints in the timber trusses, is exposed through the ratio $\mathrm{B} / \mathrm{C}$ which represents the ratio of the obtained costs (masses) between truss $\mathrm{B}$ (considering joint flexibility) and $\mathrm{C}$ (neglecting joint flexibility).

Table 2: $\quad$ Comparison of timber mass and total costs.

\begin{tabular}{cccc}
\hline \multicolumn{2}{c}{ costs ratio } & \multicolumn{2}{c}{ timber mass ratio } \\
\hline $\mathrm{B} / \mathrm{A}$ & $\mathrm{B} / \mathrm{C}$ & $\mathrm{B} / \mathrm{A}$ & $\mathrm{B} / \mathrm{C}$ \\
1.198 & 1.076 & 1.151 & 1.095 \\
\hline
\end{tabular}

From the results presented in Table 1 it is evident, that truss A represents the best solution. At the final result the deflection constraints are not active i.e. the ULS design conditions are decisive. A lower span/depth ratio of the truss is thus more favourable. Despite lower timber mass and total costs, the vertical deflections of Truss A are considerably smaller when compared to the deflections of truss B. However, both the results of trusses A and B show a significant influence of joint flexibility on the final displacements. When joint flexibility is considered, the deflections increase by over 30 percent (truss A).

Comparing trusses $\mathrm{B}$ and $\mathrm{C}$, it is evident that the influence of fastener flexibility should not be neglected at all. The total costs increase by $7.6 \%$, and the timber mass by almost $10 \%$. It should be noted, that a more detailed study, presented in [16], has shown, that the influence of joint flexibility increases with a higher number of flexibly connected bracing members (diagonals and verticals).

\section{Conclusions}

The paper presents the optimization of metal-plate-connected plane timber trusses with respect to joint flexibility. The optimization was performed by the non-linear programming approach. Since various truss design parameters like the type of truss configuration, the span/depth ratio, the number and type of diagonal and vertical members as well as the type of joint connections simultaneously affect each other, all these parameters were proposed to be simultaneously considered in a single mathematical model.

The optimization model TTO (Timber Truss Optimization) for cost optimization of timber trusses was thus developed. The economic objective function was defined in order to minimize the structure's self-manufacturing costs, subjected to the design, stress and deflection (in)equality constraints. The finite element equations were as the equality constraints defined for the calculation of the internal forces and the deflections of the structure. The undesirable slips in the connections of timber trusses additionally resulted in the 
reduction of truss stiffness. A stiffness matrix of the structure was therefore composed by considering the fictiously decreased cross-section areas of all the flexibly connected elements. The constraints for dimensioning the timber members were determined in accordance with Eurocode 5 in order to satisfy the requirements of both the ultimate and the serviceability limit states. The crosssection dimensions and the number of fasteners are defined as independent optimization variables. The obtained results are not only optimal, but the optimization also enables that the conditions of either the ultimate or the serviceability limit states are fully exploited and there is no reserve in the resistance of the structures. At this point the comparison between results of different truss design alternatives was performed.

The presented numerical example shows the applicability of the presented optimization approach as well as the influence of considering the fasteners' flexibility on the optimal self-manufacturing costs. Based on numerical results, it is recommended to design higher timber trusses with a lower span/depth ratio, with a smaller number of diagonal and vertical elements and, consequently, by using chord elements with smaller cross-sections.

\section{References}

[1] Hoyle RJ, Woeste FE. Wood Technology in the Design of Structures, Ames, Iowa: Iowa State University Press, 1989.

[2] El-Sheikh A. Approximate Analysis of Space Trusses. International Journal of Space Trusses 1996; 11: 321-30.

[3] Stalnaker J, Harris E. Structural Design in Wood, NY: Van Nostrand Reinchold, 1989.

[4] Steck G. Fachwerbinde aus Brettschictholz un Vollholz, Holzbauwerke: Bauteile Step 2, Konstruktionen, Details nach Eurocode 5, Düsseldorf: Fachverlag Holz, 1995.

[5] Brüninghoff $\mathrm{H}$ et al. Eine Ausführliche Erläuterung zu DIN 1052, Teil 1 bis Teil 3, Beuth -Kommentare, Berlin: Beuth Bauverlag, 1988.

[6] Schmidt LA Structural Design by Systematic Synthesis. Proceedings of $2^{\text {nd }}$ Conference on Electronic computations; NY: ASCE, 1960, 105-22.

[7] Lipson SL, Agrawai KM. Weight Optimization of Plane Trusses. ASCE Journal of the Structural Division 1974; 100: 865-79.

[8] Prager W. Optimization of Structural Design. Journal of Optimization Theory and Applications 1970; 6: 1-21.

[9] Šilih S, Kravanja S, Bedenik BS. Shape optimization of plane trusses. In: Hendriks, MAN, Rots JG editors, Finite Elements in Civil Engineering Applications, Proceedings of the Third DIANA World Conference, Tokyo, 2002, 369-73.

[10] Kaveh A, Kalatjari V. Topology optimization of trusses using genetic algorithm, force method and graph theory. International Journal for Numerical Methods in Engineering 2003; 58: 771-91.

[11] Kravanja S, Šilih S. Optimization based comparison between composite I beams and composite trusses. Journal of Constructional Steel Research 2003; 59: 609-25. 
[12] CEN/TC 250/SC5 N173, Eurocode 5: Design of Timber Structures, Part 1-1 General rules and rules for buildings, Final draft prEN 1995-1-1, Brussels, European Committee for Standardization, 2002.

[13] Brooke A, Kendrick D, Meeraus A. GAMS - A User's Guide, Redwood City, CA: Scientific Press, 1988.

[14] EN 1194, Timber structures - Glued laminated timber - Strength classes and determination of characteristic values, Brussels, European Committee for Standardization, 1999.

[15] Drud AS. CONOPT - A Large-Scale GRG Code. ORSA Journal on Computing 1994; 6:207-16, 1994.

[16] Šilih S, Premrov M, Kravanja S. Optimum design of plane timber trusses considering joint flexibility. Engineering structures 2005; 27: 145-154. 